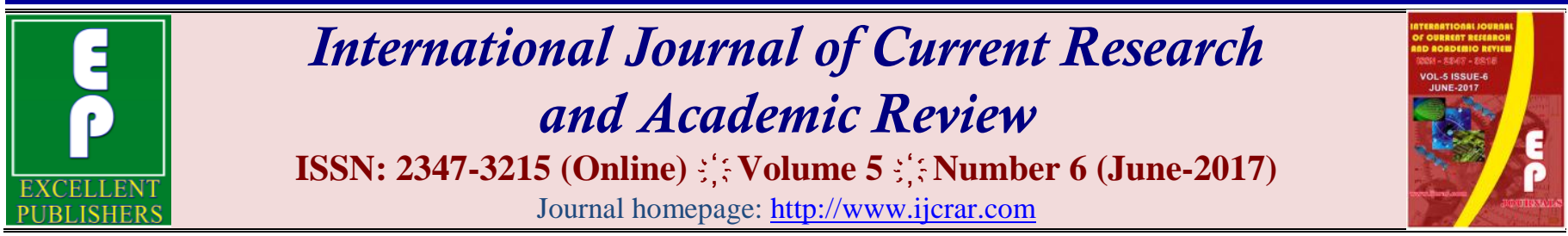

doi: https://doi.org/10.20546/ijcrar.2017.506.001

\title{
Ultrasonic and Conductometric Studies of Aqueous Potassium Chloride Solutions at Different Temperatures
}

\author{
Manoj Kumar Praharaj ${ }^{1}$, Abhiram Satapathy ${ }^{1}$ and Ilyas Ahmed ${ }^{2}$ \\ ${ }^{1}$ Department of Physics, ABIT, CDA, Sector-1, Cuttack, Odisha, India - 753014 \\ ${ }^{2}$ Department of Electrical Engineering, ABIT, India \\ *Corresponding author
}

\section{Abstract}

The electrical conductivity $(\sigma)$, ultrasonic velocity $(U)$, density $(\rho)$ and viscosity $(\eta)$ have been measured for the aqueous potassium chloride solutions at different temperatures and at frequency $4 \mathrm{MHz}$ for different concentration of $\mathrm{KCl}$. The experimental data's have been used for study of the molecular interaction in the different solutions using different parameters such as adiabatic compressibility, free length, acoustic impedance and relaxation time. Variation in the above parameters for the different solutions at different temperature is indicative of the nature of interaction between them.
\end{abstract}

\section{Article Info}

Accepted: 05 June 2017

Available Online: 20 June 2017

\section{Keywords}

Electrical conductivity, Ultrasonic velocity, Acoustic impedance, Surface tension.

\section{Introduction}

Ultrasonic method finds extensive application in investigating various physicochemical parameters involving molecular interactions in liquid solutions. Now a day, ultrasonic studies are extensively used for characterizing the thermodynamic properties of liquid solutions (Praharaj et al., 2012; 2013a,b; 2014a,b; 2015; 2016; Nath, 2009; Ali, 1996; Dash, 2014). This method plays an important role in understanding the nature of molecular interactions. This technique has also been used in biomedical engineering, agriculture and medicine. In engineering it is used to study the structure of materials. Ultrasonic pulses can speed up certain chemical reactions and act as a catalytic agent in wheat germination. Velocity of sound waves in a medium is fundamentally related to the binding forces between the molecules.

Human body needs many minerals known as essential minerals. These are further divided in two groups, major minerals (like $\mathrm{Na}, \mathrm{K} \ldots$...) and micro minerals (like Fe, $\mathrm{Si}, \ldots)$. The latter is required in small amounts than the former. Potassium is a very significant body mineral, important to both cellular and electrical function. It is one of the main blood minerals called "electrolytes" (the others are sodium and chloride). This means it carries a tiny electrical charge (potential). Potassium is the primary positive ion found within the cells, where 98 percent of the 120 grams of potassium contained in the body is found. The blood serum contains about 4-5 mg. (per $100 \mathrm{ml}$.) of the total potassium; the red blood cells contain $420 \mathrm{mg}$. This is why a red-blood-cell level is a better indication of an individual's potassium status than the commonly used serum level.

Conductivity is the ability of an aqueous solution to carry an electrical current. Conductivity measurement is an extremely widespread and useful method for quality control purposes. Surveillance of feed water purity, control of drinking water quality, estimation of total 
number of ions in a solution can all be performed using conductivity measurements. The measurement of conductivity is a rapid and inexpensive way of determining the ionic strength of a solution.

The present paper deals the study of interaction between molecules of $\mathrm{KCl}$ and water at different temperatures for various concentrations of $\mathrm{KCl}$.

\section{Materials and Methods}

The chemicals used in the present work were analytical reagent (AR). The various concentrations of the binary mixtures were prepared in terms of $\%(\mathrm{w} / \mathrm{w})$. Water used was prepared by distilling ordinary water thrice over alkaline $\mathrm{KMnO}_{4}$ in all glass apparatus. The specific conductance of water so obtained was $1.3 \times 10^{-4} \mathrm{~cm}^{-1}$.

The experimental set up for the acoustical and electrical study of liquids using ultrasonic interferometer and conductivity meter is shown in figure 1 .

Conductivity measurements are carried out using Conductivity meter. Before and after measurements, the instrument was calibrated with $\mathrm{NaCl}$ solution. Each measurement was repeated three times and the average values were calculated. Ultrasonic velocity at different temperatures were measured by using an ultrasonic interferometer (Model M-84, supplied by M/S Mittal Enterprises, New Delhi) with the accuracy of $\pm 0.1 \mathrm{~m} \cdot \mathrm{s}^{-1}$. The densities of the mixtures were measured using a $10 \mathrm{ml}$ specific gravity bottle by relative measurement method with an accuracy of $\pm 0.01 \mathrm{~kg} \cdot \mathrm{m}^{-3}$. An Oswald viscometer $(10 \mathrm{ml})$ was used for the viscosity measurement with an accuracy of $\pm 0.001 \mathrm{Ns} \cdot \mathrm{m}^{-2}$. Standard equations are used for calculation of density and viscosity.

The electrical conductivity, density, viscosity, and ultrasonic velocity were measured as a function of concentration of $\mathrm{KCl}$ at $288 \mathrm{~K}, 298 \mathrm{~K}$ and $308 \mathrm{~K}$.

\section{Parameters}

Following parameters were calculated from the above measurements of ultrasonic velocity, density and viscosity at different temperatures.

$$
\text { i. Adiabatic compressibility: } \quad \beta=\frac{1}{\rho \cdot U^{2}}
$$

Where ' $\rho$ ' is density and ' $U$ ' is the ultrasonic velocity. ii. Intermolecular free length:

$L_{f}=\mathrm{K}_{T-\beta^{2}}^{\frac{1}{2}}$

Where, $\mathrm{K}_{\mathrm{T}}=\left\{(93.875+0.375 . \mathrm{T}) \times 10^{-8}\right\}$ is Jacobson's temperature dependent constant and ' $\beta$ ' is the adiabatic compressibility.

iii. Acoustic impedance:

$\mathrm{Z}=\mathrm{U} \cdot \rho$

iv. Relaxation time:

$\tau=4 / 3(\beta \eta)$

Where, $\eta$ is the viscosity of solution

\section{Results and Discussion}

The experimental data's of electrical conductivity, ultrasonic velocity, density and viscosity of aqueous solution of potassium chloride at different temperatures are shown in table 1 . The calculated values of adiabatic compressibility, free length, acoustic impedance and relaxation time are presented in table 2 .

Velocity increases, when concentration of $\mathrm{KCl}$ increases at a particular temperature and also increases when temperature increases at a particular concentration. The increase in the ultrasonic velocity usually indicates a greater association of the component molecules. The greater association is due to ionic hydration of the solute. $\mathrm{KCl}$ is strong electrolytes which dissolve in water to form $\mathrm{K}+, \mathrm{Cl}$ - ions respectively. A greater cohesion in the solution is introduced as water molecules are attached to the ions strongly by electrostatic forces of interaction (Gupta, 2014). Variation of ultrasonic velocity with concentration of $\mathrm{KCl}$ is presented in figure 2 .

As presented in table 2, the increase of density and viscosity with increase in concentration of $\mathrm{KCl}$, suggests a strong electrolytic interaction between solute and solvent molecules. With increase in temperature, there is a decrease in intermolecular force due to increase in thermal energy of the system which results in decrease in density and viscosity. The value of adiabatic compressibility $(\beta)$ decreases with increase in concentration of $\mathrm{KCl}$ and also with increase in temperature due to structural changes of molecules in the mixture. This also confirms the increase in 
intermolecular forces. Variation of adiabatic compressibility with concentration of $\mathrm{KCl}$ is presented in figure 3 . The free length decrease with increasing solute concentration indicates a significant interaction between solute and solvent molecules and hence a structure promoting behavior on the addition of solute. Acoustical impedance $(Z)$ increases with increase in concentration of $\mathrm{KCl}$. This behavior becomes accountable for the transmission of ultrasonic waves. Relaxation time $(\tau)$ increases with increase in concentration of the salt. The relaxation time which is in the order of $10^{-12} \mathrm{sec}$ is due to structural relaxation process (Kinsler, 1989) and in such a condition it is suggested that the molecules get rearranged due to co-operative process (Ali, 2000).
The conductivity may provide information regarding the nature and strength of forces existing between the ions. Variation of conductivity with concentration of $\mathrm{KCl}$ at different temperatures is shown in figure 4 . The conductivity increases with increase in concentration of $\mathrm{KCl}$. The increase in conductivity depends on the solvent added and the extent to which the ions are dissociated. Electrical conductivity also increases as temperature increases for a particular concentration of $\mathrm{KCl}$. Conductivity of ionic liquids increases due to the presence of water-rich regions. With increase in temperature, water evaporates and thus the conductivity increases.

Table.1 Experimental values of $\sigma, \mathrm{U}, \rho$ and $\eta$ at different temperatures for aqueous solution of $\mathrm{KCl}$

\begin{tabular}{|c|c|c|c|c|c|c|c|c|c|c|c|c|}
\hline \multirow{2}{*}{$\begin{array}{c}\text { Concentratio } \\
n \text { of } \mathrm{KCl} \\
\text { by percent }\end{array}$} & \multicolumn{3}{|c|}{$\sigma / \mathrm{mScm}^{-1}$} & \multicolumn{3}{|c|}{$\mathrm{U} / \mathbf{m}, \mathbf{s}^{-1}$} & \multicolumn{3}{|c|}{ P / Kg.m ${ }^{-3}$} & \multicolumn{3}{|c|}{$\eta \times 10^{-3} / \mathrm{NSm}^{-2}$} \\
\hline & 288 & & & & & & & & 288 & 298 & 308 & 318 \\
\hline & 57.6 & 64.4 & 717 & 1501. & & & 1007. & 1004. & 1000. & 1.41. & 1.07 & 0.748 \\
\hline & $10 \%$ & 116. & & 1513. & 1518. & 1025. & 1010. & 1007. & 1003. & 1.443 & 1.09 & 0.772 \\
\hline $15 \%$ & 140 & 156. & 163. & 1516. & 1521. & 1527. & 1014. & 1011. & 1007. & 1.471 & 1.11 & 0.785 \\
\hline $20 \%$ & 183. & 190. & 198. & 1521. & 1527. & 1532. & 1018. & 1015. & 1011 & 1.501 & 1.14 & 0.798 \\
\hline $25 \%$ & 213. & 220. & 227. & 1525. & 1530. & 1535. & 1022. & 1019. & 1014. & 1.528 & 1.17 & 0.812 \\
\hline
\end{tabular}

Table.2 Calculated values of $\beta, \mathrm{Lf}, \mathrm{Z}$ and $\tau$ at different temperatures for aqueous solution of $\mathrm{KCl}$

\begin{tabular}{|c|c|c|c|c|c|c|c|c|c|c|c|c|}
\hline \multirow{2}{*}{$\begin{array}{c}\text { Concentrati } \\
\text { on of KCl }\end{array}$} & \multicolumn{3}{|c|}{$\beta \times \mathbf{1 0}^{-10} / \mathbf{N}^{-1} \mathbf{m}^{2}$} & \multicolumn{3}{|c|}{$\mathbf{L}_{\mathbf{f}} \times \mathbf{1 0}^{-10} / \mathbf{m}$} & \multicolumn{3}{|c|}{$\mathbf{Z}^{\mathbf{1 0}} \mathbf{1 0}^{\mathbf{6}} / \mathbf{K g m}^{-2} \mathbf{s e c}^{-1}$} & \multicolumn{3}{|c|}{$\tau \times \mathbf{1 0}^{-12} / \mathbf{s e c}$} \\
\cline { 2 - 14 } & 288 & 298 & 308 & 318 & 288 & 298 & 308 & 318 & 288 & 298 & 308 & 318 \\
\hline $5 \%$ & 4.404 & 4.389 & 4.383 & 0.4114 & 0.4149 & 0.4232 & 1.5126 & 1.5125 & 1.5109 & 8.215 & 6.270 & 4.360 \\
\hline $10 \%$ & 4.322 & 4.307 & 4.292 & 0.4076 & 0.4110 & 0.4187 & 1.5290 & 1.5292 & 1.5294 & 8.296 & 6.289 & 4.407 \\
\hline $15 \%$ & 4.285 & 4.264 & 4.254 & 0.4054 & 0.4090 & 0.4167 & 1.5395 & 1.5397 & 1.5400 & 8.383 & 6.335 & 4.446 \\
\hline $20 \%$ & 4.238 & 4.223 & 4.214 & 0.4036 & 0.4069 & 0.4149 & 1.5504 & 1.5505 & 1.5490 & 8.461 & 6.414 & 4.477 \\
\hline $25 \%$ & 4.204 & 4.189 & 4.183 & 0.4019 & 0.4053 & 0.4134 & 1.5596 & 1.5598 & 1.5570 & 8.543 & 6.530 & 4.522 \\
\hline
\end{tabular}


Fig.1 Experimental set up for acoustical and electrical study of liquids using Ultrasonic interferometer and conductivity meter

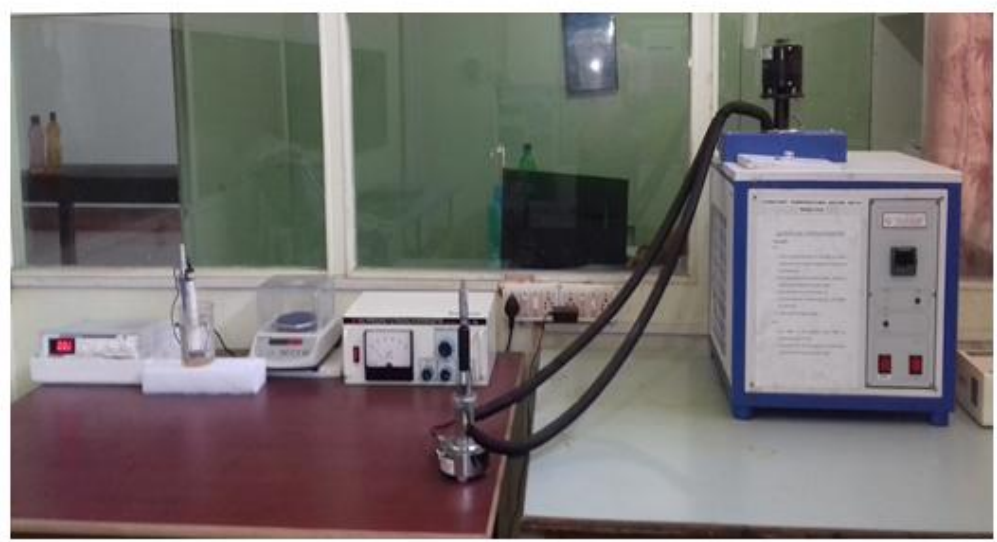

Fig.2 Variation of ultrasonic velocity with Conc. of $\mathrm{KCl}$

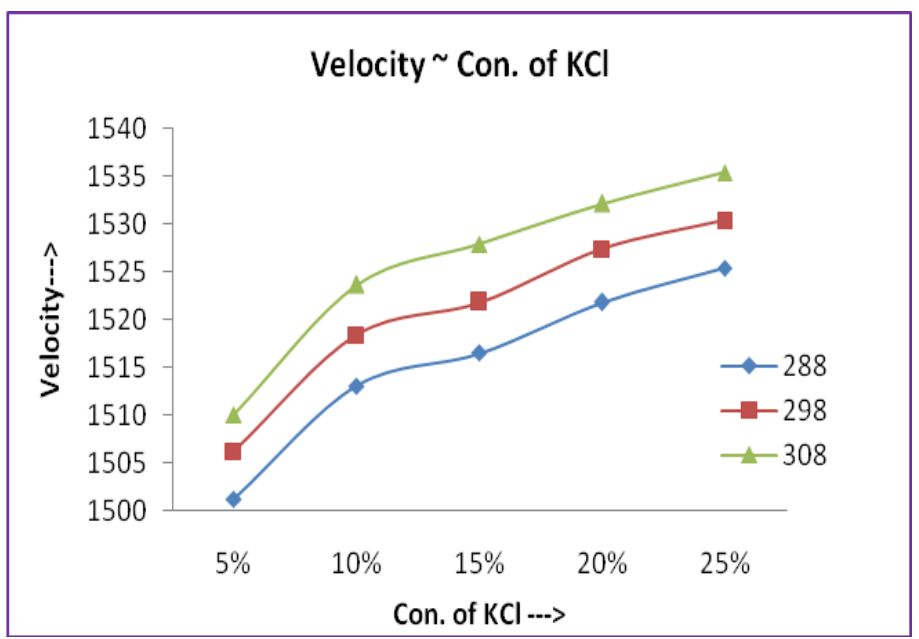

Fig.3 Variation of adiabatic compressibility with conc. of $\mathrm{KCl}$

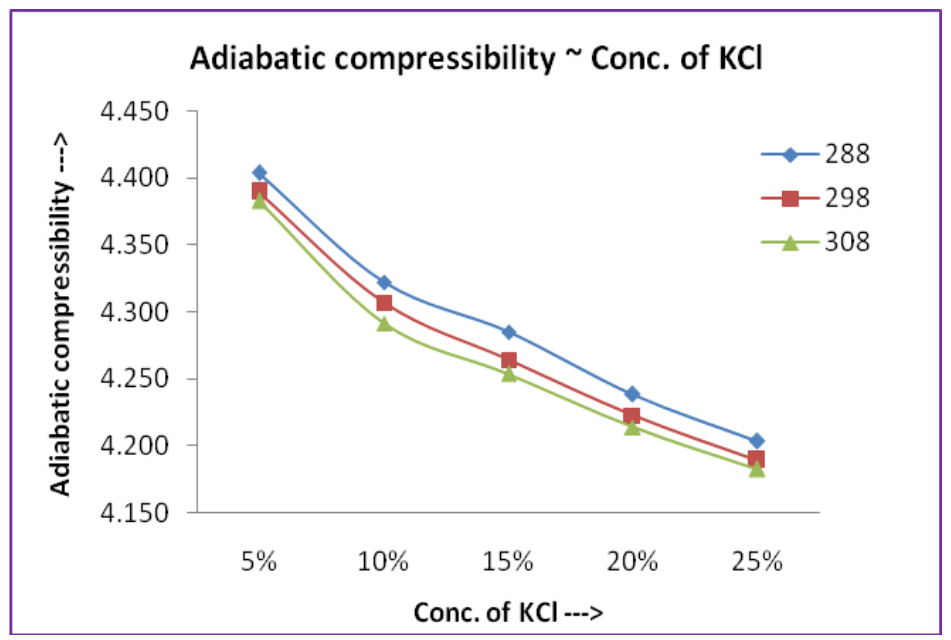

Fig.4 Variation of electrical conductivity with concentrated of $\mathrm{KCl}$

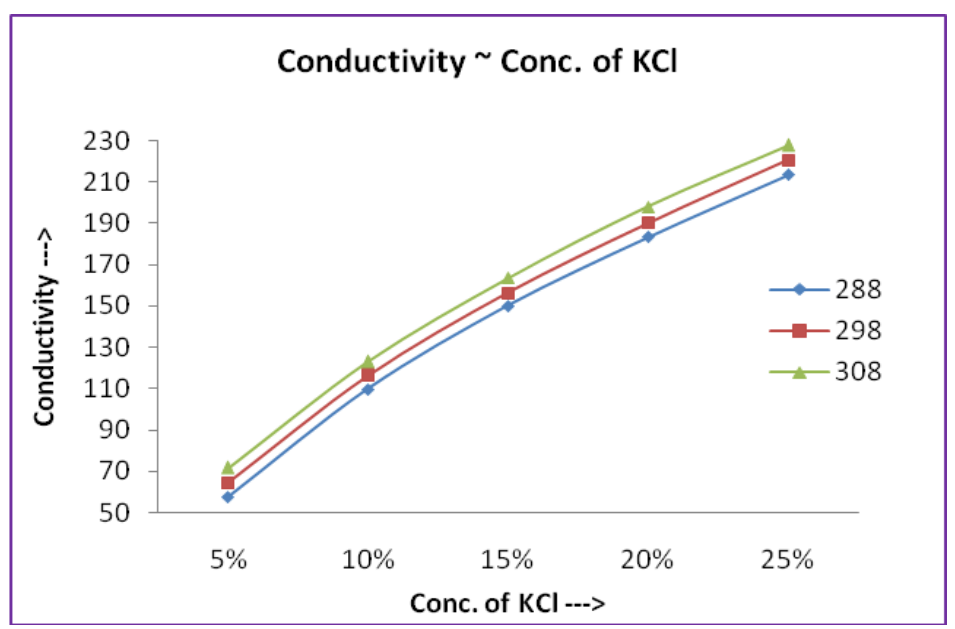




\section{Conclusion}

The results of the present study signify that the ultrasonic velocity and derived acoustic parameters depend on composition of the solution, which indicates the presence of molecular interaction between the component molecules. The computed acoustical parameters and their values point to the presence of specific molecular interactions in the solutions.

\section{Acknowledgement}

The authors are thankful to R\&D cell and Management of Ajay Binay Institute of Technology, CDA, Cuttack, for providing the infrastructure for the improvement of research activities in the Institute.

\section{References}

Ali, A, Hyder, S., Nain, A.K. 2000. Indian J Phys., 74(B): 63.

Ali, A. Nain, A.K. 1996. Ultrasonic study of molecular interactions in $\mathrm{N}$, N-dimethylacetamide+ethanol binary mixtures at various temperatures, Acoust. Lett., 19: 181.

Dash, A.K.,Paikaray, R. 2014. Studies on Acoustic Parameters of Ternary Mixture of Dimethyl Acetamide in Acetone and Isobutyl Methyl Ketone using Ultrasonic and Viscosity Probes, Int. J. of Chem. \&Phy Sc., 3: 69-79.

Gupta, V., Sharma, A.K., Sharma, M. 2014. Comparative Ultrasonic and Conductometric Studies of Aqueous Sodium Chloride and Potassium Chloride Solutions", Chemical Science Transactions, 3(2): 736-744.

Kinsler, L.E., Rray, A.R. 2000. Fundamentals of Acoustics, Wiley Eastern, New Delhi,1989.

Praharaj, M.K., Satapathy, A., Mishra, P., Mishra, S., 2012. Ultrasonic Studies of Molecular Interactions in pyridine $+\mathrm{N}-\mathrm{N}$ dimethylformamide + cyclohexane Ternary Liquid Mixtures at Different Temperatures", Journal of Theoretical and Applied Physics (Springer open Journal), 7: 1-6.

Praharaj, M.K., Satapathy, A., Mishra, P., Mishra S. 2013a. Ultrasonic analysis of intermolecular interaction in the mixtures of benzene with $n, n-$ dimethylformamide and cyclohexane at different temperatures", J of Chem.\& Phar. Res.,5: 49-56.

Praharaj, M.K., Satapathy, A., Mishra, P., Mishra, S. 2013b. Study of molecular interaction in mixture of $\mathrm{n}$, n-dimethylformamide, cyclohexane and benzene for different frequencies of ultrasonic waves, Golden Research Thoughts, 2: 1-10.

Praharaj, M.K., Mishra S. 2014a. Study of acoustic and thermodynamic parameters for binary mixture containing cyclohexane and the substituted benzenes at different temperatures, $\mathrm{J}$ Chem. Bio.\&Phy. Sc., Section C, 5: 686-699.

Praharaj, M.K., Satapathy, A., Mohanty, J., Mishra, S. 2014b. Thermodynamic Parameters and Their Excess Values for Binary Mixtures of Cyclohexane Plus Benzene and Substituted Benzenes at Different Ultrasonic Frequencies, Int. J of Eng. Res.\& Tech, 3: 1060-1065.

Praharaj, M.K., Mishra S. 2015. Molecular interaction in ternary liquid mixtures at different temperatures, World journal of pharmacy and pharmaceutical sciences, 5: 1597-1607.

Praharaj, M.K., Mishra S. 2016. Ultrasonic Study of Certain Binary Mixtures In Terms of the Excess Values of Thermodynamic Parameters. Int. J Recent Sci. Res. 7: 9125-9128. Nath, G.,Paikaray, R. 2009. Effect of frequency on acoustic parameters in a binary mixture of polar liquids, Indian J. of Phys., 83: $1567-1574$.

\section{How to cite this article:}

Manoj Kumar Praharaj, Abhiram Satapathy, Ilyas Ahmed. 2017. Ultrasonic and Conductometric Studies of Aqueous Potassium Chloride Solutions at Different Temperatures. Int.J.Curr.Res.Aca.Rev. 5(6), 1-5.

doi: https://doi.org/10.20546/ijcrar.2017.506.001 